\title{
Prognostic Significance of Serum PSA Level and Telomerase, VEGF and GLUT-1 Protein Expression for the Biochemical Recurrence in Prostate Cancer Patients after Radical Prostatectomy
}

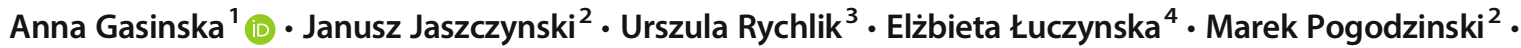 \\ Mikolaj Palaczynski ${ }^{2}$
}

Received: 27 November 2018 / Accepted: 1 April 2019 / Published online: 15 April 2019

(C) The Author(s) 2019

\begin{abstract}
The aim of the study was to evaluate prognosis for biochemical recurrence (BR) by analysing the pathological and biological characteristics of prostate cancer (PCa) after radical prostatectomy (RP). There were 130 men with clinically localized PCa in whom pretreatment serum PSA level and Ki-67, prostate specific membrane antigen (PSMA), glucose transporter-1 (GLUT-1), vascular endothelial growth factor (VEGF), microvessel density (MVD) and human telomerase reverse transcriptase (hTERT) proteins expression, based on number of immunohistochemically positive cells (labelling index), were retrospectively studied. In order to assess the prognostic significance of analysed variables in univariate and multivariate Cox analysis, patients were dichotomized based on cut-off points chosen by receiver operating characteristic (ROC) curves. There were 83 males $(63.8 \%)$ at pT stage 1-2 and 47 (36.1\%) at pT stage 3-4, respectively, with median (range) age of 62.8 years (49-77), and median followup of 78.5 months (12-148). In $42(32.3 \%)$ men BR was found. In univariate analysis, tumour biological features: PSA $\leq 8$ ng/ $\mathrm{mL}(p=0.006), \mathrm{Ki}-67 \mathrm{LI} \leq 12.7 \%(p=0.015)$, VEGFLI $>11.0 \%(p=0.030)$, and hTERTLI $>6.7 \%(p=0.016)$, but not clinicopathological parameters, appeared to be positive prognosticators for BRFS. In the Cox analysis, Ki-67 lost its significance, and clinicopathological parameters appeared to be nonsignificant. The independent negative prognostic factors for BRFS were: PSA $>8.0 \mathrm{ng} / \mathrm{mL}$, (Hazard ratio $=2.75, p=0.003)$, GLUT-1 $>19.1 \%(\mathrm{HR}=2.1, p=0.032), \mathrm{VEGF} \leq 11.0 \%(\mathrm{HR}=1, p=$ $0.024)$ and $\mathrm{hTERT} \leq 6.7 \%(\mathrm{HR}=1, p=0.017)$. High PSA level, and GLUT-1 expression and lower VEGF and nuclear hTERT expression may indicate the great role of hypoxia in BR induction in PCa.
\end{abstract}

Keywords Prostatic carcinoma · Biochemical failure · PSA · GLUT-1 · VEGF · hTERT

\section{Introduction}

Prostate cancer ( $\mathrm{PCa})$, the most common malignancy in males, is characterized by intratumoral heterogeneity and a

Anna Gasinska

z5gasins@cyf-kr.edu.pl

1 Department of Tumour Pathology, Oncology Center, Maria Sklodowska - Curie Institute, Cracow Branch, Garncarska 11, 31-115, Cracow, Poland

2 Department of Surgery, Oncology Center, Maria Sklodowska - Curie Institute, Cracow Branch, Cracow, Poland

3 Department of Clinical Biochemistry, Oncology Center, Maria Sklodowska-Curie Institute, Cracow Branch, Cracow, Poland

4 Department of Radiology, Oncology Center, Maria Sklodowska-Curie Institute, Cracow Branch, Cracow, Poland viable clinical course. Traditionally, prostate cancer diagnosis is based on prostate specific antigen (PSA) determination and clinicopathological factors (histology, tumour size, Gleason scores and clinical staging). However, there are remarkable differences in the biological behavior of prostate cancers classified as the same grade and stage, as clinical prognostic groupings for localized PCa are imprecise. Therefore, reliable distinction between indolent and aggressive PCa prior to treatment implementation is not achievable [1]. In low-advanced $\mathrm{PCa}$, both radiotherapy (RT) and radical prostatectomy (RP) are primary treatment modalities. However, RP remains the gold standard for curative treatment of PCa because it significantly reduces mortality, the risk of local progression and the onset of distant metastasis [2].

Prostate-specific antigen (PSA) has been generally used for screening of PCa, post diagnostic PSA surveillance or monitoring following treatment. Cancer progression defined by 
elevated PSA level (two consecutive PSA levels $\geq 0.2 \mathrm{ng} /$ $\mathrm{mL}$ ), otherwise known as biochemical recurrence (BR), is almost always the earliest sign of recurrent $\mathrm{PCa}$ and can predate either clinical or radiographic evidence of disease by months to years following RP or radiotherapy [3, 4]. However, qualification to treatment of individual patient is imprecise and $30-50 \%$ of patients have biochemical relapse within 10-years after RP or image-guided radiotherapy [5, 6], which would never progress to clinical metastasis. Therefore, it is now considered, that PSA has limited diagnostic and prognostic value and a low specificity and sensitivity resulting in frequent misdiagnosis [3]. Furthermore, PSA test has limitations including lack of standardization of screening as serum levels exhibit relatively wide biological variations and PSA levels do not accurately predict disease aggressiveness (different PSA cut-off points and frequency of screening schedules) $[1,3]$. Also the test has potential harms for prostate cancer screening and patients' follow-up (overdiagnosis - false positive, complications of unnecessary biopsy) or overtreatment (surgery, radiation treatment) $[3,4]$.

Therefore, the availability of better prognostic biomarkers may also greatly aid the treatment decision process for $\mathrm{PCa}$ patients. Early recognition based on biological markers could be helpful not only in identification of biological differences in benign and malignant lesions, offering further help in precise indication for more aggressive post-operative treatment (chemo/radiotherapy) but also for assessment of BR risk. Immunohistochemical expressions of many molecular tissue markers in PCa have been studied, such as: cyclooxygenase 2, P53, Ki-67, BCL2 and microvessel density [7-9], but their actual clinical usefulness has not yet been conclusively validated and approved for routine assessment [10]. In another study, BR was associated with tumour aggressive features in the DNA-based and RNA-based signatures to measure genomic instability [11]. Recently, radiomics or computerextracted texture features derived from magnetic resonance imaging (MRI) [12] or metabolomics [13] have been shown to help quantitatively characterize $\mathrm{PCa}$ and predict $\mathrm{BR}$ or malignancy of $\mathrm{PCa}$.

Earlier, we checked, based of pretreatment PSA level and immunohistochemical analysis of 6 proteins, if it is possible to select, before RP, more aggressive tumours for more aggressive treatment. We showed that increase of pathological tumour volume and tumour grade was associated with statistically significant increase in serum PSA, Ki-67 [14] and prostate specific membrane antigen (PSMA) expression [15], however, for telomerase enzyme activity (human telomerase reverse transcriptase, a catalytic subunit of telomerase, hTERT) the relation was opposite, indicating extranuclear telomere activity independent of telomere lengthening, and suggesting that it cannot be considered as a marker of malignancy [15]. However, significantly higher vascular endothelial growth factor (VEGF) was observed in pT3 and pT4 than in pT1 stage [16] indicating induction of angiogenesis and endothelial cell growth, as it is considered to be hypoxiainducible pro-angiogenic protein [17]. Microvessel density (MVD/CD34) and glucose transporter -1 through the cell membrane (GLUT-1) were not significantly correlated with tumour volume and grade $[14,16]$. Therefore, the aim of the present project is to check, in the same patient cohort, the possibility of showing prognostic significance of pretreatment PSA level, Ki-67LI, MVD, VEGFLI, GLUT-1LI, PSMALI and hTERT activity in PCa for the frequency of biochemical relapses and patients' biochemical recurrence-free survival (BRFS). In order to avoid predetermined cutoff point for biological variables, receiver operating characteristic (ROC) curve analysis was applied.

\section{Material and Methods}

\section{Patients and Samples}

The studied population consisted of a retrospective cohort of 130 PCa patients who had RP surgery between 2007 -2011 and in whom tumour biopsy was taken during curative surgery. Tumours were classified according to clinical $\mathrm{T}$ category (cTNM) and pathological (pTNM) stages, according to the American Joint Committee on Cancer (AJCC) guidelines and Gleason score. The protocol was approved by the Ethical Committee of the Centre of Oncology, and each patient submitted written consent.

\section{Immunohistochemical Analysis and Scoring}

Protein expression was evaluated immunohistochemically on histological specimens, using the suitable antibody and BrightVision visualization system (ImmunoLogic). For Ki67 visualization we used a mouse-antiKi-67 monoclonal antibody (clone MIB-1, DAKO, 1:75), for GLUT-1 a rabbit monoclonal antibody (Millipore, 1:300), for CD34 a mouse anti-human monoclonal antibody (DAKO, 1:200), for VEGF a mouse anti-VEGF monoclonal antibody (DAKO, 1:25), for hTERT a rabbit polyclonal antibody to human telomerase (Novus Lab. Biologicals, Littleton, USA), (1:300) and for PSMA a mouse anti-human prostate specific membrane antigen (Novocastra, Newcastle, United Kingdom)(1:200), diluted in TRIS-buffered saline $(\mathrm{pH}=7.4)$, as described earlier [14-16]. Proteins expression was presented as the number of positively staining cells (labelling index, LI) of nuclear (Ki67, hTERT), membrane (PSMA, CD34), membrane/ cytoplasmic (GLUT-1) and cytoplasmic (VEGF) staining 
and MVD (CD34 immunoreactivity) as a mean vessel count per $1 \mathrm{~mm}^{2}$ of tumour volume. Slides were evaluated by two investigators who were unaware of the clinicopathological variables.

\section{Evaluation of Follow-Up}

After surgery, patients were followed with PSA measurements at 3 and 6 months, then every 6 months for 2 years, and thereafter yearly or until biochemical recurrence (BR). No patients received adjuvant hormonal or radiation therapy before BR was confirmed. BRFS was the time calculated from the date of surgery to BR, which was defined as detectable serum PSA (greater than $0.2 \mathrm{ng} / \mathrm{mL}$ ), as documented by repeated PSA measurements.

\section{Statistical Analysis}

Statistical analysis was performed with STATISTICA vs 12 (StatSoft Inc. Tulusa, OK, USA). To determine mean values for variables and standard errors of means (SE) we used the descriptive statistics. One-way ANOVA test or Student's t test were applied to test intergroup differences in the mean values. The correlations between proteins expression were tested with Pearson correlation and between proteins expression and other variables with Spearman rank test. Associations between investigated categorical parameters and clinicopathological variables were evaluated by Pearson's $\mathrm{Chi}^{2}$ test. For sensitivity and specificity of each marker receiver, curve analyses (ROC curves) were performed to determine the area under the curve (AUC) as a measure of diagnostic accuracy. For BRFS analysis patients were stratified into two groups based on cutoff points for each variable optimized by ROC curve.

\section{Selection of Cutoff Score}

ROC curve analysis was utilized to determine cutoff value for separating tumors with abnormal proteins expression from tumors with normal expression by using the 0 . 1-criterion. The sensitivity and specificity for each outcome under study was plotted, thus generating various ROC curves with areas under curve (AUCs). The score was selected as the cutoff value, which was closest to the point with both maximum sensitivity and specificity. Tumors designated as "normal expression" were those with scores below or equal to the cutoff value, while tumors which "overexpression" were those with scores above the value. In order to perform ROC curve analysis, the clinicopathologic features were dichotomized: age $(\leq 61.0$ or $>61.0$ years $)$, AJCC tumor grade $(\mathrm{G} 1$ or $\mathrm{G} 2$ / 3), TNM stage (T1-2 or T3-4), pTNM (pT1/2 or pT3/4). Survival was estimated using the Kaplan-Meier method and tested by the log-rank test. A univariate and multivariate Cox proportional model was conducted to further explore the relationship between proteins expression and the BRFS. In multivariate analysis, clinical and biological variables were first tested separately and finally all variables together. Statistical significance was considered at $p$ value of 0.05 .

\section{Results}

A total of 130 patients with a median age of 62.0 years were eligible for this study. (Table 1). During a median follow-up of 78.5 (range 12.0-148.0) months, 42 (32.3\%) patients developed BR within 8-86 month (median 35) months after RP. The clinicopathological characteristics of the patients are summarized in Table 1 . There was no statistically significant difference between age and clinicopathological variables between patients with and without BF, except Gleason score; a higher number of more anaplastic tumours had BF (Table 1).

The mean values of biomarkers were given in Table 2 . There was no statistically significant difference in the mean values of biomarkers in patients who were PSA failure positive and negative (Table 2).

\section{Correlation between Clinical and Biological Variables}

The expression level of PSA $(p=0.030), \mathrm{Ki}-67(p=0.024)$, PSMA $(p<0.001)$, GLUT-1 $(p=0.037)$ were positively and hTERT $(p=0.033)$ negatively correlated with the Gleason score. Only PSA $(p=0.007)$ and PSMA $(\mathrm{p}<0.001)$ were positively correlated with cT and pT stage $(\mathrm{p}<0.001)$. VEGF expression was not linked to any clinicopathological variables. Further correlation analysis showed that in our cohort, only the expression of PSA was positively correlated with $\mathrm{Ki}$ $67(p=0.014)$. There were no significant correlations between the expressions of other markers .

\section{Selection of Cutoff Points}

According to the ROC curve, the cutoff points for the analysed biomarkers: PSA, Ki-67, CD34, GLUT-1, VEGF, PSMA, hTERT were defined for $8 \mathrm{ng} / \mathrm{mL}, 12.7 \%, 82.5$ microvessels $/ \mathrm{mm}^{2}, 19.1 \%, 11.0 \%, 49.3 \%$ and $6.7 \%$, respectively.

The ROC curve for the value of the following biomarkers in prediction of postoperative biochemical recurrence of $\mathrm{PCa}$ showed the AUC to be 0.635 (95\% CI: 0.534-0.736), with a sensitivity of $73.2 \%$ and a specificity of $56.2 \%$ for PSA, 0.564 (95\% CI: $0.451-0.679$ ), with a sensitivity of $29.3 \%$ and a specificity of $89.9 \mathrm{x} \%$ for Ki-67, 0.450 (95\% CI: $0.343-$ 0.556 ), with a sensitivity of $61.0 \%$ and a specificity of 
Table 1 Clinicopathological characteristics of 130 patients with $\mathrm{PCa}$ treated with radical prostatectomy (comparison between biochemical recurrence (BR) - positive versus BRnegative subgroups)

\begin{tabular}{|c|c|c|c|c|}
\hline Characteristics & Total $N=130(\%)$ & $\begin{array}{l}\text { BR-negative* } \\
N=88\end{array}$ & $\begin{array}{l}\text { BR-positive** } \\
N=42\end{array}$ & $p$ value \\
\hline $\begin{array}{l}\text { Median age, years } \\
\text { (range) } \\
\text { cT stage }\end{array}$ & $\begin{array}{l}(130) 62.0 \\
(49-77)\end{array}$ & $\begin{array}{l}62.0 \\
(50.0-75.0)\end{array}$ & $\begin{array}{l}64.0 \\
(49.0-77.0)\end{array}$ & 0.368 \\
\hline $\begin{array}{l}\mathrm{T} 1 \\
\mathrm{~T} 2 \mathrm{~A}\end{array}$ & $\begin{array}{l}11(8.5) \\
14(10.8)\end{array}$ & $\begin{array}{l}8(9.1) \\
10(11.4)\end{array}$ & $\begin{array}{l}3(7.1) \\
4(9.5)\end{array}$ & 0.554 \\
\hline $\mathrm{T} 2 \mathrm{~B}$ & $57(43.8)$ & $38(43.2)$ & $19(45.2)$ & \\
\hline $\mathrm{T} 3$ & $37(28.5)$ & $26(29.5)$ & $11(26.2)$ & \\
\hline $\mathrm{T} 4$ & $10(7.7)$ & $5(5.7)$ & $5(11.9)$ & \\
\hline $\mathrm{Tx}$ & $1(0.8)$ & 1 & 0 & \\
\hline \multicolumn{5}{|l|}{ pT stage } \\
\hline $\begin{array}{l}\text { pT1 } \\
\text { pT2 }\end{array}$ & $\begin{array}{l}12(9.2) \\
71(54.6)\end{array}$ & $\begin{array}{l}9(10.2) \\
47(53.4)\end{array}$ & $\begin{array}{l}3(7.1) \\
24(57.1)\end{array}$ & \multirow[t]{3}{*}{0.606} \\
\hline pT3 & $38(29.2)$ & $28(31.8)$ & $10(23.8)$ & \\
\hline pT4 & $9(6.9)$ & $4(4.5)$ & $5(11.9)$ & \\
\hline \multicolumn{5}{|c|}{ Histological grade AJCC } \\
\hline $\begin{array}{l}1 \\
2\end{array}$ & $\begin{array}{l}69(53.1) \\
49(37.7)\end{array}$ & $\begin{array}{l}51(57.9) \\
30(34.1)\end{array}$ & $\begin{array}{l}18(42.8) \\
19(45.2)\end{array}$ & \multirow[t]{2}{*}{0.087} \\
\hline 3 & $12(9.2)$ & $7(7.9)$ & $5(11.9)$ & \\
\hline \multicolumn{5}{|l|}{ Gleason Score } \\
\hline $\begin{array}{l}\leq 6 \\
7\end{array}$ & $\begin{array}{l}67(51.5) \\
50(38.5)\end{array}$ & $\begin{array}{l}51(57.3) \\
31(34.8)\end{array}$ & $\begin{array}{l}17(40.5) \\
19(45.2)\end{array}$ & \multirow[t]{2}{*}{0.047} \\
\hline$\geq 8$ & $13(10.0)$ & $7(7.9)$ & $6(14.3)$ & \\
\hline
\end{tabular}

$*$ PSA $<=0.2 \mathrm{ng} / \mathrm{mL}, * *$ PSA $>0.2 \mathrm{ng} / \mathrm{mL}$
24.7\% for CD34, 0.512 (95\% CI: 0.403-0.620), with a sensitivity of $70.7 \%$ and a specificity of $44.9 \%$ for GLUT-1, 0.505 (95\% CI: $0.394-0.618$ ), with a sensitivity of $52.4 \%$ and a specificity of $64.1 \%$ for PSMA, 0.536 (95\% CI: $0.432-$ 0.640 ), with a sensitivity of $63.4 \%$ and a specificity of

Table 2 Tumour biological characteristics and pretreatment PSA levels in patients with biochemical recurrence (BR-positive) and without BR (BR- negative)

\begin{tabular}{lllll}
\hline Characteristics & $\begin{array}{l}\text { Total } \\
N=130 \\
\text { Mean } \pm \text { SE }\end{array}$ & $\begin{array}{l}\text { BR- } \\
\text { negative } \\
N=88 \\
\text { Mean } \pm \text { SE }\end{array}$ & $\begin{array}{l}\text { BR- } \\
\text { positive } \\
N=42 \\
\text { Mean } \pm \text { SE }\end{array}$ & $p$ value* \\
\hline PSA ng/mL & $9.9 \pm 0.5$ & $9.4 \pm 0.6$ & $10.8 \pm 0.7$ & 0.195 \\
Ki-67 (\%) & $8.1 \pm 0.6$ & $7.3 \pm 0.6$ & $9.7 \pm 1.3$ & 0.092 \\
GLUT-1(\%) & $30.4 \pm 2.1$ & $29.6 \pm 2.4$ & $31.9 \pm 3.8$ & 0.603 \\
VEGF (\%) & $15.1 \pm 1.4$ & $16.1 \pm 1.8$ & $12.8 \pm 2.3$ & 0.281 \\
MVD/mm ${ }^{2}$ & $97.1 \pm 2.5$ & $99.1 \pm 3.1$ & $92.8 \pm 3.9$ & 0.234 \\
PSMA (\%) & $44.6 \pm 2.0$ & $44.6 \pm 2.2$ & $44.8 \pm 3.9$ & 0.950 \\
hTERT (\%) & $18.3 \pm 1.6$ & $20.3 \pm 2.0$ & $14.3 \pm 2.3$ & 0.075 \\
\hline
\end{tabular}

*Difference between BR- positive and negative subgroups (t-test)
$52.8 \%$ for VEGF, 0.615 (95\% CI: $0.512-0.718$ ), with a sensitivity of $73.0 \%$ and a specificity of $46.3 \%$ for telomerase.

\section{Univariate and Multivariate Analysis}

Kaplan-Meier analysis showed the actuarial patients'10-year BRFS as $60 \%$. In log-rank test PSA $\leq 8 \mathrm{ng} / \mathrm{mL}(p=0.006)$, Ki$67 \mathrm{LI} \leq 12.7 \%(p=0.015)$, hTERTLI $>6.7 \%(p=0.016)$ and VEGFLI $>11.0 \%(p=0.030)$ were positive statistically significant prognosticators for BRFS (Fig. 1). An univariate Cox proportional model was conducted to further explore the relationship between proteins expression and BF. In the analysis, PSA, Ki-67, VEGF and hTERT appeared to be important prognostic factors for BRFS (Table 3). When only clinicopathological variables were included in Cox analysis, positive prognosticators for BRFS were: cT1-2 $(p=0.024)$, pT $1-2$ $(p=0.018)$, and Gleason score $<7(p=0.043)$. However, when PSA was added, only PSA became independent prognostic factor $(p=0.005)$. When all clinical and biological parameters were analysed together, none of the clinical and pathological features of $\mathrm{PCa}$ was shown to have greater impact on patients' BRFS than tumour biological features. High pretreatment levels of serum PSA (> $8 \mathrm{ng} / \mathrm{mL}$ ), GLUT-1LI (>19.1\%) 

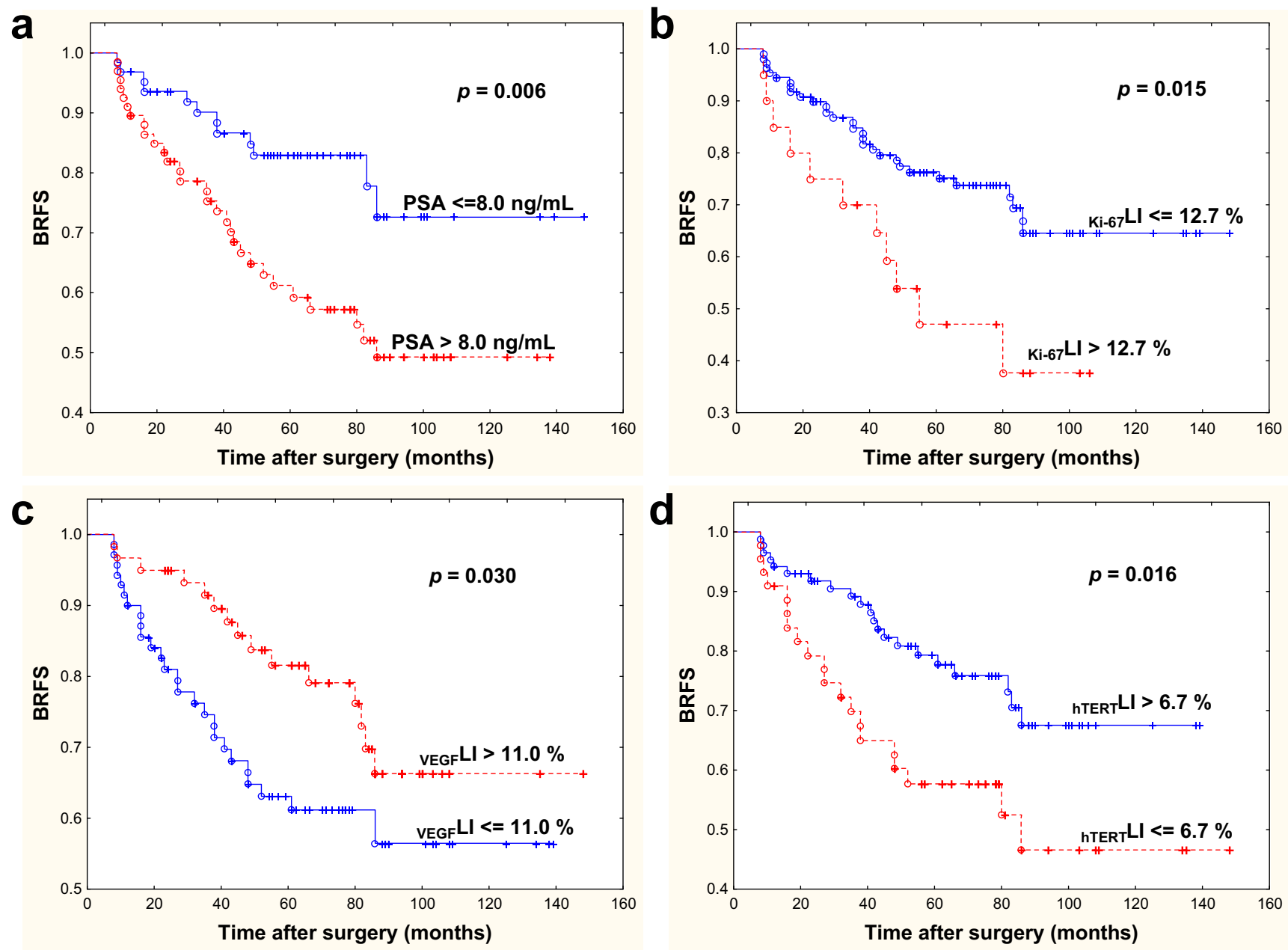

Fig. 1 Prognostic significance of PSA (a), Ki-67 (b), VEGF (c), hTERT (d), for biochemical recurrence-free survival (BRFS) in prostate cancer patients treated with radical prostatectomy ( $p$ value from log-rank test)

and lower hTERT $(\leq 6.7 \%)$ and VEGF $(\leq 11.0 \%)$ expression were significant predictors for shorter time to BR on multivariate analysis (Table 3).

\section{Discussion}

We analysed the prognostic value of pretreatment serum PSA level and expression of 6 proteins for BRFS of low and intermediate risk PCa patients after RP. We have shown that none of the analyzed clinical and pathological features of $\mathrm{PCa}$ was shown to have a greater impact on patients' BRFS than tumour biological features, which is in agreement with recently published studies showing greater significance of biomarkers than clinic-pathological features in risk assessment for BR after RP $[6,11,18]$.

We showed that high PSA levels $(>8 \mathrm{ng} / \mathrm{mL}$ ) and tumour hypoxia (GLUT-1 $>19.1 \%$ ) or lower nuclear hTERTLI $(\leq 6.7 \%)$ and VEGFLI $(\leq 11.0 \%)$ expression were negative prognostic factors for BRFS. In the multivariate analysis the PSA level $>8.0 \mathrm{ng} / \mathrm{mL}$ and higher fraction of hypoxic cells (GLUT-1 $>19.1 \%)$ doubled the risk $(\mathrm{HR}=2)$, while higher VEGF and nuclear hTERT expression reduced by half $(\mathrm{HR}=0.5)$ the risk of biochemical recurrence in PCa patients after prostatectomy. All these indicate the great role of hypoxia in induction of BR in PCa.

In our cohort, the overall PSA recurrence rate was $32.3 \%$ which is within the range (25.1-41.0\%) given by other authors $[6,7,9,19]$. In our study cohort the median follow-up was 79 (range 12-148) months, and 10-year BRFS rate was 60\% which is within the rage given by other authors [6, 20,21]. Also median time to BR of 35 (range 8.00-86.0) months was similar as in other reports after RP $[7,9,13]$ or after RT (68.9\%) [20]. Our study indicated that GS and pT stage were not useful predictive factors for BRFS which may be in agreement with some studies [6] although in contrast with other [7]. 
Table 3 Cox proportional hazards analysis of the biological and clinicopathological features of prostate cancer predicting biochemical recurrence-free survival in men with localized PCa

\begin{tabular}{llllllll}
\hline Variable & \multicolumn{2}{l}{ Univariate analysis } & & \multicolumn{2}{l}{ Multivariate analysis } \\
\cline { 2 - 3 } \cline { 5 - 7 } & $\mathrm{RR}$ & $95 \% \mathrm{CI}$ & $p$ value* & & $\mathrm{RR}$ & $95 \% \mathrm{CI}$ & $p$ value \\
\hline
\end{tabular}

\begin{tabular}{|c|c|c|c|c|c|c|}
\hline \multicolumn{7}{|l|}{ Age (years) } \\
\hline$\leq 61.0$ & 1.00 & Reference & & & & \\
\hline$>61.0$ & 1.20 & $0.65-2.20$ & 0.550 & & & \\
\hline \multicolumn{7}{|l|}{ AJCC Grade } \\
\hline 1 & 1.00 & Reference & & & & \\
\hline $2-3$ & 1.78 & $0.96-3.32$ & 0.070 & & & \\
\hline \multicolumn{7}{|l|}{ Clinical stage } \\
\hline cT1-2 & 1.00 & Reference & 0.929 & & & \\
\hline cT3-4 & 1.03 & $0.55-1.92$ & & & & \\
\hline \multicolumn{7}{|c|}{ Pathological stage } \\
\hline pT1-2 & 1.00 & Reference & & & & \\
\hline pT3-4 & 0.91 & $0.48-1.71$ & 0.765 & & & \\
\hline \multicolumn{7}{|l|}{ PSA } \\
\hline$\leq 8.0 \mathrm{ng} / \mathrm{mL}$ & 1.00 & Reference & & 1.00 & Reference & \\
\hline$>8.0 \mathrm{ng} / \mathrm{mL}$ & 2.53 & $1.29-4.96$ & 0.006 & 2.75 & $1.40-5.43$ & 0.003 \\
\hline \multicolumn{7}{|l|}{ Ki-67LI } \\
\hline$\leq 12.7 \%$ & 1.00 & Reference & & & & \\
\hline$>12.7 \%$ & 2.35 & $1.17-4.69$ & 0.015 & & & \\
\hline \multicolumn{7}{|l|}{ GLUT-1LI } \\
\hline$\leq 19.1 \%$ & 1.00 & Reference & & 1.00 & Reference & \\
\hline$>19.1 \%$ & 1.63 & $0.83-3.13$ & 0.143 & 2.10 & $1.1-4.1$ & 0.032 \\
\hline \multicolumn{7}{|l|}{ VEGF } \\
\hline$\leq 11.0 \%$ & 1.00 & Reference & & 1.00 & Reference & \\
\hline$>11.0 \%$ & 0.53 & $0.28-1.00$ & 0.030 & 0.46 & $0.24-0.90$ & 0.024 \\
\hline \multicolumn{7}{|l|}{ MVD } \\
\hline$\leq 82.5 / \mathrm{mm}^{2}$ & 1.00 & Reference & & & & \\
\hline$>82.5 / \mathrm{mm}^{2}$ & 0.68 & $0.36-1.27$ & 0.225 & & & \\
\hline \multicolumn{7}{|l|}{ PSMA } \\
\hline$\leq 49.3 \%$ & 1.00 & Reference & & & & \\
\hline$>49.3 \%$ & 1.30 & $0.69-2.34$ & 0.428 & & & \\
\hline \multicolumn{7}{|l|}{ hTERT LI } \\
\hline$\leq 6.7 \%$ & 1.00 & Reference & & 1.00 & Reference & \\
\hline$>6.7 \%$ & 0.47 & $0.25-0.87$ & 0.016 & 0.47 & $0.25-0.87$ & 0.017 \\
\hline
\end{tabular}

Abbreviations: $R R$ risk ratio, $C I$ confidence interval

This discrepancy in the statistical power of clinicopathological variables maybe caused by different inclusion criteria in other studies, analysis of bigger patients population with advanced and G4 tumours, too short follow-up or use of different levels for PSA BR (np. $0.1 \mathrm{ng} / \mathrm{mL}$ or $0.4 \mathrm{ng} / \mathrm{mL}$ instead of $0.2 \mathrm{ng} /$ $\mathrm{mL}$ ). However, the most important difference is caused by inclusion of tumour biological parameters to the multivariate analysis. Therefore, researchers are currently trying to understand (on molecular level) why some men with prostate cancer go on to develop aggressive disease with high risk of $\mathrm{PCa}$ death, whilst others maintain slow growing tumours [1].

Our study shows that increased PSA level was negative prognosticator for BR, as also shown in some studies [19-22] and its significance was not indicated in other [12, $18,23]$. Our ROC analysis showed the highest sensitivity (70$80 \%$ ) for PSA, GLUT-1, and hTERT however, the highest specificity was indicated for Ki-67 (89.9\%) and PSMA $(61.4 \%)$. In our study, expression of proliferation marker Ki-67 positively correlated with PSA suggesting that PSA, through androgen receptor, may result in promotion of $\mathrm{PCa}$ growth [24]. Ki-67 appeared to be negative prognostic factor for patients' BRFS, but only in univariate analysis. In multivariate analysis however, we could not confirm its prognostic value which is in agreement with some authors results $[9,10]$ though in disagreement with other studies where prognostic value of Ki-67, among others, but not hypoxic biomarkers were indicated [7]. We suggest, after other authors, that hypoxia in $\mathrm{PCa}$ might have more predictive power than proliferation [6].

There is general agreement that various factors regulate angiogenesis in PCa. We studied VEGF expression to evaluate the angiogenic activity of $\mathrm{PCa}$ and have shown that a higher VEGF expression was a good prognosticator for patients' BRFS which may suggest prognostic value of tumour remodeling and better oxygenation. Therefore, we assume, after other authors, that higher VEGF expression might be stimulated by cellular hypoxia [17] or androgens [25].

We did not observe the correlation between VEGF and the extent of hypoxia. However, in other study it was showed that androgens may activate hypoxia inducible factor -1 alph (HIF1alpha) protein at the very early stage of prostate tumorigenesis which driving VEGF expression in androgen sensitive human prostate cancer [26]. In our study VEGF expression was not associated with tumour malignancy, tumour volume or pT stage which is in agreement with other studies [27]. Also MVD, as determined by CD34 antibody, was not correlated with tumour grade and $\mathrm{pT}$ stage and appeared to be non useful prognostic factor for patients' BRFS as shown in some earlier study [23].

Tumour cells exist within a heterogenous tumour microenvironment with dynamic gradient of hypoxia that has been linked to malignant potential. This was shown in our study where GLUT-1 expression was associated with tumour grade and appeared to be independent negative prognosticator for BRFS. This finding supports earlier studies based on DNA signature [11], also those showing that hypoxic tumours fail to react to radiotherapy treatment and are at risk of BR [6]. Hypoxia also affects hTERT expression, the catalytic subunit of human telomerase, the lowest expression of which was observed in G3 tumours presenting the highest GLUT-1 expression. Our study demonstrated that higher nuclear expression of hTERT may be a good prognosticator for BRFS that 
may support finding that telomeres plays an important role in mitochondrial biology [28]. TERT under oxidative stress is reversibly excluded from the nucleus to mitochondria (nuclear-mitochondrial shuttling of TERT), where it is accumulated (lower nuclear TERT expression) and involved in the protective role in antioxidative stress, improvement of mitochondrial function, and better cell survival $[28,29]$. Another explanation for our results is a hypothesis that telomerase activity is regulated by androgens and the wild-type human androgen receptor inhibits the expression of hTERT in the presence of androgen receptor agonists [30]. This may be true, as we observed it in our patients with anaplastic tumours, the highest PSA levels and the lowest nuclear hTERT expression [15].

Earlier we showed that higher PSMA expression in higher pTNM stages and tumour grades may indicate PSMA as a good marker of biological aggressiveness suitable for patients' selection for more aggressive treatment [15]. However, now we are unable to show utility of PSMA for predicting patients' prognosis for BRFS which is in agreement with some studies [22]. We could not indicate significant association between PSMA and tumour proliferation (Ki-67) which may be in line with other authors findings [22] and support the speculation that high expression of PSMA may be associated with unfavourable tumour phenotype such as hypoxia and be related with PCa development rather than progression [22]. Therefore, our data do not suggest a clinical utility of PSMA measurements for predicting patient prognosis. In our study, lack of significance of PSMA may be caused by relatively low number of analysed advanced PCa or the relatively low PSMA expression, which could be inhibited by a high level of pretreatment PSA. The negative relationship between PSMA and PSA was suggested by in vitro study. This may suggest that in patients with high testosterone or dihydrotestosterone level, low PSMA expression can be observed which may complicate easy application of PSMA/PET method, recommended recently for identification of localized recurrent PCa.

Our study supports a unique role of PCa tumour biology. Due to heterogeneity of $\mathrm{PCa}$ it is possible that a combination of biomarkers may provide better predictive value, which agrees with recent studies made on molecular level [11, 18]. However, these findings have to be confirmed by further analysis of prostate cancer-specific mortality or time to metastasis. Our study indicates the great role of hypoxia in BR induction in PCa. We first demonstrated that high pretreatment serum PSA level and high GLUT-1 expression or lower VEGF, and nuclear hTERT expression were negative predictors for 10year BRFS rate in patients after RP. Therefore, we suggest to use these biomarkers for evaluating the patients' prognosis. However, in our study PSA specificity for malignancy was only $56.2 \%$ and sensitivity $-73.3 \%$. Therefore, it should be stressed that interval from PSA recurrence to metastasis is quite long and not every biochemical relapse leads to metastasis, because biochemical recurrences do not always form the most malignant neoplasms [21]. Therefore, only when $\mathrm{PCa}$ patients from high-risk group for BR develop metastases and have shorter OS, the prognostic significance of the biomarkers will be confirmed, and only then it will be possible to qualify patients to salvage therapy (for example with hypoxiaactivated prodrugs), based on hypoxia biomarkers, instead of active surveillance.

\section{Conclusion}

High pretreatment serum PSA and tumour hypoxia (high GLUT-1 expression or lower VEGF and lower nuclear hTERT expression) were negative prognosticators for biochemical recurrence-free survival in PCa patients after radical prostatectomy.

Author's Contribution Protocol/project development: A Gasinska, J. Jaszczyński. Data collection..J Jaszczynski, U. Rychlik, E. Luczynska, M. Pogodzinski, M. Palaczynski. Data analysis: A Gasinska, U. Rychlik, M. Pogodzinski. Manuscript writing/editing: all authors. A. Gasinska is acknowledged for supervision.

\section{Compliance with Ethical Standards}

Conflict of Interest The authors declare that they have no conflict of interest.

Ethical Approval The study protocol was approved by the local Ethical Committee at the Regional Medical Chamber in Cracow. All procedures performed in the study involving human participants were in accordance with the ethical standards of the institutional and/or national research committee and with the 1964 Declaration of Helsinki and its later amendments or comparable ethical standards.

Informed Consent Informed consent was obtained from all individuals included in the study.

Open Access This article is distributed under the terms of the Creative Commons Attribution 4.0 International License (http:// creativecommons.org/licenses/by/4.0/), which permits unrestricted use, distribution, and reproduction in any medium, provided you give appropriate credit to the original author(s) and the source, provide a link to the Creative Commons license, and indicate if changes were made.

\section{References}

1. Mahal BA, Yang DD, Wang NQ, Alshalalfa M, Davicioni E, Choeurng V, Schaeffer EM, Ross AE, Spratt DE, den RB, Martin NE, Mouw KW, Orio PF 3rd, Choueiri TK, Taplin ME, Trinh QD, Feng FY, Nguyen PL (2011) Clinical and genomic characterization of low-prostate-specific antigen, high-grade prostate cancer. Eur Urol 74:146-154. https://doi.org/10.1016/j.eururo.2018.01.043

2. Bill-Axelson A, Holmberg L, Ruutu M, Häggman M, Andersson SO, Bratell S, Spångberg A, Busch C, Nordling S, Garmo H, Palmgren J, Adami HO, Norlén BJ, Johansson JE (2005) Radical prostatectomy versus watchful waiting in early prostate cancer. $\mathrm{N}$ 
Engl J Med 352(19):1977-1984. https://doi.org/10.1056/ NEJMoa043739

3. Duffy MJ (2014) PSA in screening for prostate cancer: more good than harm or more harm than good? Adv Clin Chem 66:1-23

4. Xia J, Trock B, Gulati R et al (2014) Overdetection of recurrence after radical prostatectomy: estimates based on patient and tumor characteristics. Clin Cancer Res 20. https://doi.org/10.1158/10780432.CCR-13-3366

5. Shao Y-H, Demissie K, Shih W, Mehta AR, Stein MN, Roberts CB, DiPaola RS, Lu-Yao GL (2009) Contemporary risk profile of prostate cancer in the United States. J Natl Cancer Inst 101:1280-1283. https://doi.org/10.1093/jnci/djp262

6. Vergis R, Corbishley CM, Norman AR, Bartlett J, Jhavar S, Borre M, Heeboll S, Horwich A, Huddart R, Khoo V, Eeles R, Cooper C, Sydes M, Dearnaley D, Parker C (2008) Intrinsic markers of tumour hypoxia and angiogenesis in localized prostate cancer and outcome of radical treatment: a retrospective analysis of two randomized radiotherapy trials and one surgical cohort study. Lancer Oncol 9: 342-351. https://doi.org/10.1016/S1470-2045(08)70076-7

7. Kim SH, Park WS, Park BR, Joo J, Joung JY, Seo HK, Chung J, Lee KH (2017) PSCA, Cox-2, and Ki-67 are independent, predictive markers of biochemical recurrence in clinically localized prostate cancer: a retrospective study. Asian J Androl 19(4):458-462. https://doi.org/10.4103/1008-682X.180798

8. Bettencourt MC, Bauer JJ, Sesterhenn IA, Mostofi FK, McLeod DAG, Moul JW (1996) Ki-67 expression is a prognostic marker of prostate cancer recurrence after radical prostatectomy. J Urol 156:1064-1068

9. Leon P, Cancel-Tassin G, Drouin S et al (2018) Comparison of cell cycle progression score with two immunohistochemical markers (PTEN and Ki-67) for predicting outcome in prostate cancer after radical prostatectomy. World J Urol 36:1495-1500. https://doi.org/ $10.1007 / \mathrm{s} 00345-018-2290-\mathrm{y}$

10. Kristiansen G (2012) Diagnostic and prognostic molecular biomarkers for prostate cancer. Histopathol 60:125-141

11. Lalonde E, Ishkanian AS, Sykes J, Fraser M, Ross-Adams H, Erho N, Dunning MJ, Halim S, Lamb AD, Moon NC, Zafarana G, Warren AY, Meng X, Thoms J, Grzadkowski MR, Berlin A, Have CL, Ramnarine VR, Yao CQ, Malloff CA, Lam LL, Xie H, Harding NJ, Mak DYF, Chu KC, Chong LC, Sendorek DH, P'ng C, Collins CC, Squire JA, Jurisica I, Cooper C, Eeles R, Pintilie M, Dal Pra A, Davicioni E, Lam WL, Milosevic M, Neal DE, van der Kwast T, Boutros PC, Bristow RG (2014) Tumour genomic and microenvironmental heterogeneity for integrated prediction of 5-year biochemical recurrence of prostate cancer: a retrospective cohort study. Lancet Oncol 15:1521-1532. https://doi.org/10.1016/S14702045(14)71021-6

12. Shiradkar R, Ghose S, Jambor I, Taimen P, Ettala O, Purysko AS, Madabhushi A (2018) Radiomic features from pretreatment biparametric MRI predict prostate cancer biochemical recurrence: preliminary findings. J Magn Reson Imaging 48:1626-1636. https://doi.org/10.1002/jmri.26178

13. Vandergrift LA, Decelle EA, Kurth J, Wu S, Fuss TL, DeFeo EM, Halpern EF, Taupitz M, McDougal WS, Olumi AF, Wu CL, Cheng LL (2018) Metabolomic prediction of human prostate cancer aggressiveness: magnetic resonance spectroscopy of histologically benign tissue. Sci Rep 8:4997. https://doi.org/10.1038/s41598018-23177-w

14. Luczynska E, Gasinska A, Wilk W (2012) Expression of Ki-67 (MIB-1) and GLUT-1 proteins in non-advanced prostatic Cancer. Pol J Pathol 63:272-277

15. Gasinska A, Luczynska E, Wilk W, Cichocka A (2013) Expression of telomerase and prostate-specific membrane antigen in nonadvanced prostatic Cancer. Folia Histochem Cytobiol 51:66-72. https://doi.org/10.5603/FHC.2013.0010
16. Luczynska E, Gasinska A, Wilk W (2013) Microvessel density and vascular endothelial growth factor expression in clinically localized prostate cancer. Pol J Pathol 1:33-38

17. Gordan JD, Simon MC (2007) Hypoxia-inducible factors: central regulatirs of the tumor phenotype. Curr Opin Genet Dev 17:71-77. https://doi.org/10.1016/j.gde.2006.12.006

18. Abou-Ouf H, Alshalalfa M, Takhar M, Erho N, Donnelly B, Davicioni E, Karnes RJ, Bismar TA (2018) Validation of 10-gene molecular signature for predicting biochemical recurrence and clinical metastasis in localized prostate. J Cancer Res Clin Oncol 144: 883-891. https://doi.org/10.1007/s00432-018-2615-7

19. Stackhouse GB, Sesterhenn IA, Bauer JJ et al (1999) p53 and BCL2 immunohistochemistry in pretreatment prostate needle biopsies to predict recurrence of prostate cancer after radical prostatectomy. J Urol 162:2040-2045

20. Tsan D-L, Fan K-H, Chen Y-C et al (2013) Pre-radiotherapy PSA level as a predictor for biochemical control in prostate Cancer patients receiving radiotherapy after radical prostatectomy. Biom J 36: 71-76

21. Roehl KA, Han M, Ramos CG et al (2004) Cancer progression and survival rates following anatomical radical retropubic prostatectomy in 3,478 consecutive patients: long-term results. J Urol 172: 910-914. https://doi.org/10.1097/01.ju.0000134888.22332.bb

22. Minner S, Wittmer C, Graefen M, Salomon G, Steuber T, Haese A, Huland H, Bokemeyer C, Yekebas E, Dierlamm J, Balabanov S, Kilic E, Wilczak W, Simon R, Sauter G, Schlomm T (2011) High level PSMA expression is associated with PSA recurrence in surgically treated prostate cancer. Prostate 71:281-288. https://doi.org/ 10.1002/pros. 21241

23. De la Taille A, Katz AE, Bagiella E et al (2000) Microvessel density as a predictor of PSA recurrence after radical prostatectomy. A comparison of CD34 and CD31. Am J Clin Pathol 113:555-562. https://doi.org/10.1309/02W2-KE50-PKEF-G2G4

24. Wen S, Niu Y, Lee SO, Chang C (2014) Androgen receptor (AR) vs negative roles in prostate cancer cell deaths including apoptosis, anoikis, entosis, necrosis and autophage cell death. Cancer Treat Rev 40:31-40. https://doi.org/10.1016/j.ctrv.2013.07.008

25. Joseph IBJK, Nelson JB, Denmeade SR et al (1997) Androgens regulate vascular endothelial growth factor content in normal and malignant prostatic tissue. Clin Cancer Res 3:2507-2511. https:// doi.org/10.1016/j.ctrv.2013.07.008

26. Mabjeesh NJ, Amir S (2007) Hypoxia-inducible factor (HIF) in human tumorigenesis. Histol Histopathol 22:559-572. https://doi. org $/ 10.14670 / \mathrm{HH}-22.559$

27. Mao K, Badoual C, Camparo P et al (2008) The prognostic value of vascular endothelial growth factor (VEGF)-A and its receptor in clinically localized prostate cancer: a prospective evaluation in 100 patients undergoing radical prostatectomy. Can J Urol 15: 4257-4262

28. Ahmed S, Passos JF, Birket MJ, Beckmann T, Brings S, Peters H, Birch-Machin MA, von Zglinicki T, Saretzki G (2008) Telomerase does not counteract telomere shortening but protects mitochondrial function under oxidative stess. J Cell Sci 121:1046-1053. https:// doi.org/10.1242/jcs.019372

29. Saretzki G (2014) Extra-telomeric functions of human telomerase: cancer, mitochondria and oxidative stress. Curr Pharm Des 20(41): 6386-6403 PMID:24975608

30. Moehren U, Papaionnou M, Reeb CA et al (2008) Wild-type but not mutant androgen receptor inhibits expression of the hTERT telomerase subunit: a novel role of AR mutation for prostate cancer development. FASEB J 22:4-1267. https://doi.org/10.1096/fj.079360com

Publisher's Note Springer Nature remains neutral with regard to jurisdictional claims in published maps and institutional affiliations. 